\title{
A Study on Designing an O2O Flipping-Classroom Pattern Under Educational Background of Big Data*
}

\author{
Ying Yue \\ Zhejiang Radio \& TV University, Zhejiang, China
}

\begin{abstract}
The from online to offline $(\mathrm{O} 2 \mathrm{O})$ flipping classroom pattern based on mobile-learning (m-learning) has been designed after the learning habits having been investigated and learning approaches of learning-platform having been chosen. And this sort of pattern which uses the convenience of the mobile terminal, in accordance with its characteristics, has already integrated the concepts of designing the micro-class, applying with education big data and using theories of social learning circle for inference. Therefore, the personalized service may provided for the users well, and the teaching may be quantized, and the learning resources may be accommodated accurately, this $\mathrm{O} 2 \mathrm{O}$ flipping classroom pattern may show more characteristics of smart learning time much better than ever.
\end{abstract}

Keywords: smart learning, from online to offline (O2O), flipping classroom, mobile-learning (m-learning)

The developments of the mobile network and the cloud-computing technologies have given the innovation of educational teaching modes newer energy. Both of the learners and their administrators have been pushed into a new learning era, in which it is quick, independent, and sharable, a smart learning era. The mobile-learning (m-learning) model which is a booming learning model will become a beneficial complement as the traditional e-learning one, and it will have the electronic-learning (e-learning) environment be more cubical. Meanwhile, the learning concept of smart learning time has been sublimated from m-learning to ubiquitous-learning (u-learning). At present, a kind of from online to offline (O2O) flipping classroom based on $\mathrm{u}$-learning regarded as the future mode of smart learning classroom is subversively creating a new learning model.

\section{The Characteristics and Advantages of O2O Flipping Classroom Based on U-Learning}

In recent years, the phrase "flipping classroom" has already been very popular. At the same time, abroad, the flipping classroom teaching has achieved greatly. Some of the elementary and primary schools, the regular higher educational institutions and the adult colleges and universities in China are taking active part in their beneficial trials and explorations now. With the rapid development of the mobile Internet technologies, the teaching reforms and learning experiences have been poured into renewed vigorous of the flipping classroom when they met the $\mathrm{O} 2 \mathrm{O}$ learning mode. Therefore, the flipping classroom mode begins to consummate and

\footnotetext{
*Acknowledgement: Thanks for the academic funds from Project of Science and Technology Department of Zhejiang Province: Research on Dynamic Interactive Painting Technology and Platform Building based on AJAX Webpage Patterning (Project No: 2007C31006); and Project of Science and Technology Department of Zhejiang Province: Teaching Platform of a Cloud Blackboard Designing for Gesture Recognition in Mobile Terminal (Project No: 2014C31068).

Ying Yue, M.Sc., assistant researcher, Department of Human Resources, Zhejiang Radio \& TV University.
} 
innovate in Internet thinking ways, and many problems of the traditional classroom teaching will be resolved in the near future. There are the following main characteristics of the $\mathrm{O} 2 \mathrm{O}$ flipping classroom:

\section{Having Flipped the Control of Learning}

In the traditional classroom, the learning content, the learning styles, the learning schedules, and so on are often controlled by the teachers, and the students are asked to learn according to their teachers' arrangements and requirements, so that the students' learning motivations are completely under the teachers' control. Just as what John Dewy (2001) said that education should be initiative and a constructive process, however, it was actually the real "to tell" and "to be told" things in the traditional classroom (p. 46). In the O2O flipping classroom, this kind of passive learning process has been overturned completely, and the students can choose their own learning time and learning rhythms in accordance with their concrete conditions, and they also can look up the pertinent learning materials or to bunch the teaching video programs, so they will control the learning initiatives finally.

\section{Having Flipped the Interactivity of Learning}

It is more important that the interactivity between the teachers and the students is vividly manifested to be tridimensional because of its interactivities in class and on online. In the $\mathrm{O} 2 \mathrm{O}$ flipping class, the teachers who have been roles of presenting the learning materials and learning instructors from the pure knowledge imparters can exchange information with the students through the learning platforms and all kinds of mobile terminals at anytime and anywhere. At the same time, these interactivities can also help the teachers understand the students, so that they can explain the important and difficult points specifically for the students in class. For the students, the $\mathrm{O} 2 \mathrm{O}$ flipping classroom model not only can provide a platform and chances of exchange information, but also it can help the students share their learning achievements one another and help them to learn cooperatively through their learning experiences. People, such as Jonathan Berman emphasized that the flipping classroom mode is not just used the videos instead of the teachers and it is more of an approach to increase the interactions between the teachers and the students (Bergmann, Overmyer, \& Wilie, 2012).

\section{Having Flipped the Lecturing Approaches}

In the traditional class, the teachers explain the knowledge predominantly and consistently, and some of the students may feed up with learning or will be able to understand completely what the teachers have explained because of the differences of the students' basic knowledge and their receptivity. Nevertheless, according to the flipping classroom mode, the students should learning the relevant knowledge points independently before class, the students can relearn in accordance with their own practical needs, and the teachers can reduce the repeated interpretation of knowledge. Consequently, the classroom efficiency may be enhanced.

\section{Having Flipped the Teachers' Roles}

The teachers in the flipping classroom are now in charge of the class organizers instead of the primary knowledge transmitters, that is to say, the change of the teachers' main role of the lecture-oriented teaching model into that of guiding and assisting the students to learn has highlighted the subjectivity of the students in $\mathrm{O} 2 \mathrm{O}$ flipping class. And the flipping class focuses on fostering the abilities, habits, thinking ways, cooperative spirit, etc. of the students' learning than ever before, therefore, the flipping classroom may suit for the talent fostering mode in the environment of constructing the learning society. 
Through the $\mathrm{O} 2 \mathrm{O}$ flipping classroom, the teaching space can be expanded from offline to online. On the basis of teaching thought of From Learning to Teaching, the abilities of how the students to think and learn independently should be cultivated well and the students' individual special roles should be played fully, so that the students' personal learning may be promoted, the students' learning activities may be stimulated, and finally the students' learning efficiency can be enhanced. In the meantime, after the $\mathrm{O} 2 \mathrm{O}$ flipping classroom model has been introduced, the innovations and reforms of teachers teaching performs will be accelerated. Therefore, teaching will suit for learning, and teaching can facilitate with learning, and teaching can serve for learning ultimately.

The O2O flipping classroom can also magnify the learning effects in class, and can heighten the linkage type drainage between the offline and the online, and can bring many high sticky learners, i.e., to drive more people to join the learning group, obviously, the comprehensive influences can be reinforced at last. Concretely, the main characteristics of the $\mathrm{O} 2 \mathrm{O}$ flipping classroom model are shown as the following: Firstly, it may improve the learning experiences and respect the students' demands for learning, and changing the disadvantages into advantages may help us quickly find the needed information, make a strategic decision, show the achievements, and make evaluation, so that the students will not be imparted knowledge by the teachers, and the students start to learn with the aimed questions of their own accord. Secondly, the learning atmosphere will be improved, and the learning circles based on social contact will be built. And thirdly, the influences will be enlarged with the combination of the learning online and the learning offline, thus, the learning information and the high grade learning materials will be share with by all of the learners, and there will appear a large number of high sticky learners, even the partners outside and costumers by learning the programs and the spread information and the learning sources.

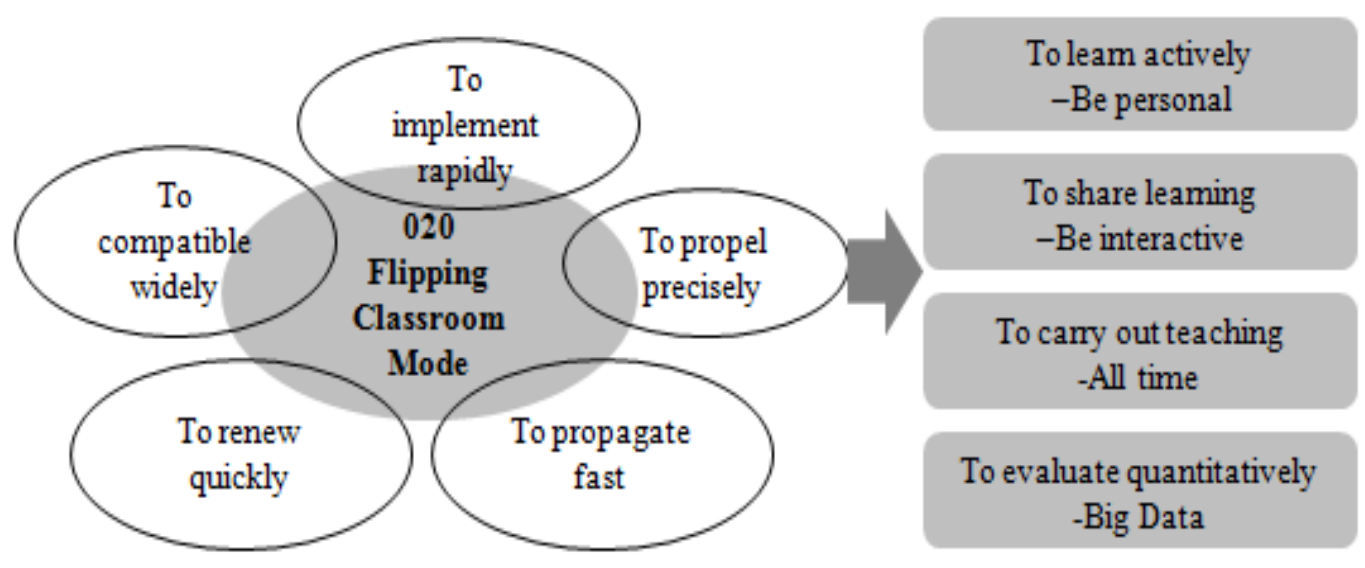

Figure 1. Advantages of the $\mathrm{O} 2 \mathrm{O}$ flipping classroom mode.

In the O2O flipping class, the students' centre position will be consolidated, i.e., the students will be encouraged to take part in the learning activities and to share with the learning achievements one another, and the exchange and communications will be more frequent than ever before, and as results, the manners of the students acquiring the learning resources and their learning feedback will be easier. In the meantime, the teaching administrators can pay attention to how to release the learning information and materials and how to supervise the students' learning progress, and that they will construct the online learning environment and learning atmosphere with more energy, and they will arouse more learning initiatives in the students. To sum 
up, both the teachers and the students will benefit from the deep reforms of the educational innovation, and all of these will exert the all-dimensional advantages of A Rapid Implement, A Quick Renew, A Fast Propagation, A Precise Propelling Movement, A Wide Compatibility, et al. accordingly, the flipping classroom model with the characteristics of "individuation," "interaction," "full-time space," and "big data" will be constructed eventually (see Figure 1).

\section{Constructing the Learning Platform of the O2O Flipping Classroom Based on M-Learning}

The O2O flipping classroom learning platform based on m-learning scientifically reconstructs and designs holistically the students' learning procedures in class and out of class, and arranges an introductory learning arrangement in class for the students. The $\mathrm{O} 2 \mathrm{O}$ flipping class schemes emphasizes that the role integrity and the manipulating usability should be combined together and entirely integrate the core roles of "mobile micro course + mobile micro examination + rapid class video + micro pile + learning communication + learner group + report form statistic," thereupon, an $\mathrm{O} 2 \mathrm{O}$ flipping classroom learning environment in which is easy to manipulate, to administrate and to preserve will be offered to the teachers and the students. Meanwhile, the strategy of carrying out flipping classroom should be supplied to the customers (the learners), and to help the customers properly to use the integrated technologies, including the implement of customizing the mobile application (APP) and the design and exploration of the micro courses. The core functions of the $\mathrm{O} 2 \mathrm{O}$ flipping classroom learning platform contain that how the teachers to administrate online, how the teacher to lecture offline, how the students to learn online and how the students to learn offline (see Figure 2).

\section{The Functions of the Administrators Online}

This kind of functional module is mainly used for designing teaching activities, uploading the teaching materials, and so on. The teachers can upload the teaching materials, such as the teaching videos, the teaching Power Points (PPTs) by the platform. At the same time, according to their needs, the teachers can also assign the learning tasks for the students, organize the learning groups, enact the evaluation criterions, etc.. And they also should commitment to answer the questions raised by the learners and instruct the learners how to learn online.

Online, the learners can carry out emulational practice through the designed virtual practice software on the knowledge points to be explained or to be manipulated in the courses. And the students can communicate remotely with the teachers through the network or the mobile APP to solve the met problems when they are learning, and the teachers can instruct the students to learn through the network or the mobile APP, too.

\section{The Functions of the Classroom Offline of the Teachers}

In the $\mathrm{O} 2 \mathrm{O}$ flipping classroom, the class offline is the best and most beneficial things for the students. Of course, this class offline is different from the traditional one, because in this class offline, the teachers promote the knowledge internalized by face-to-face teaching, and actually, in most part of time, the teachers will listen to the students' learning reports, ask for the students' work progress, answer the students' all kinds of questions, organize the students to join the thematic discussion, and so on. Simply speaking, the tasks of the offline class are to know the students' learning conditions, and to guide them how to learn online. The O2O flipping class schemes place emphasis on offering the teaching accessory appliance for the teachers in offline class, for example, it can help the teachers to assess the class quickly, etc.. 


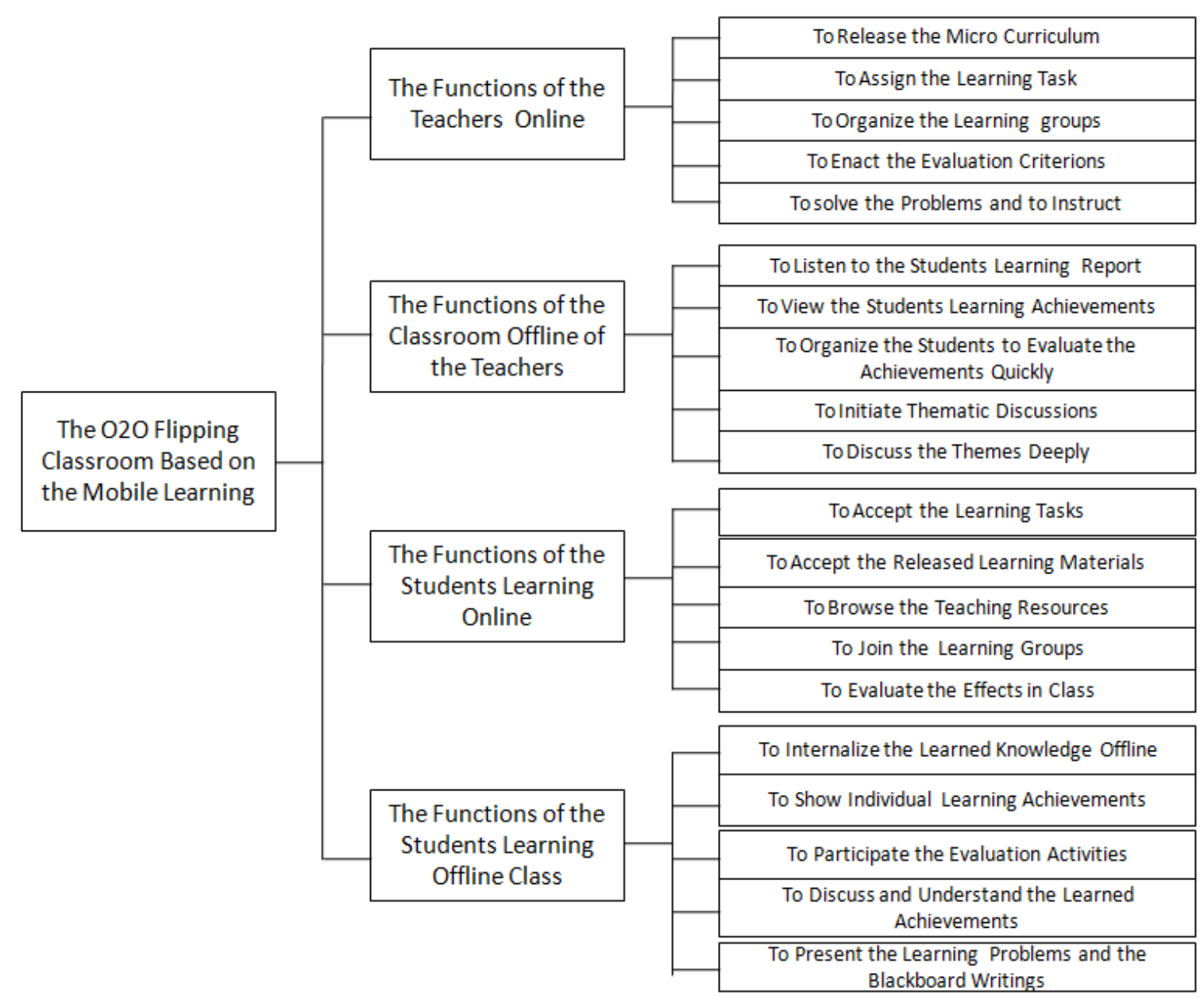

Figure 2. Mode of the $\mathrm{O} 2 \mathrm{O}$ flipping classroom teaching design based on mobile learning.

\section{The Functions of the Students Learning Online}

According to this kind of function, the students can preview the knowledge more deeply through the online learning. Before class, at first, the students should accept the learning tasks and the micro lecture materials from the teachers, and then browse and learn the teaching resources such as the teaching videos, the teaching PPTs, the micro courses, etc. with the mobile APP, and the students can also to exchange their learning information and experiences with their classmates or their teachers in their learning process at any time. And the students also can self-directed learn online. Concretely, they can know the relevant content of the courses, and then do their work assigned by their teachers. In the process of self-directed learning, the students can write down the met problems, and then solve the problems with the teachers, the classmates online together, or ask their teachers in the face-to-face classroom. In this module, the students can also replay the teaching videos, evaluate the key knowledge points and appraise the class effects through the mobile APP.

\section{The Functions of the Students Learning in Offline Class}

The students can learn independently online. After they have known the relevant knowledge points of the courses, they will internalize the knowledge through the class work offline. In offline class, the students can initiatively report what they have understood on the course content, the progress of their class work and the problems what they have met when they did their class work. 
The classmates also can discuss some question to strengthen the understanding of what they have learned from the class work. The O2O flipping classroom scheme is used to provide the students auxiliary tools for the preparation of their offline class. For example, it can be used to help the students to participate in appraising the class, presenting the learning problems quickly, and writing down all the key points shown on the blackboard, and so on.

The above four functions are shown as: guide of learning gateway, my learning, my activities, and installation to express the concepts of using the knowledge along learning, recording the learning process, strengthening to exchange the learning information and learning experiences and communicating rapidly and to help the teachers and the students accessibly step into the flipping classroom situation (see Table 1).

Table 1

The Functional Chart of O2O Flipping Classroom Learning Platform Based on M-Learning

\begin{tabular}{|c|c|}
\hline Functional modules & Detailed descriptions \\
\hline & 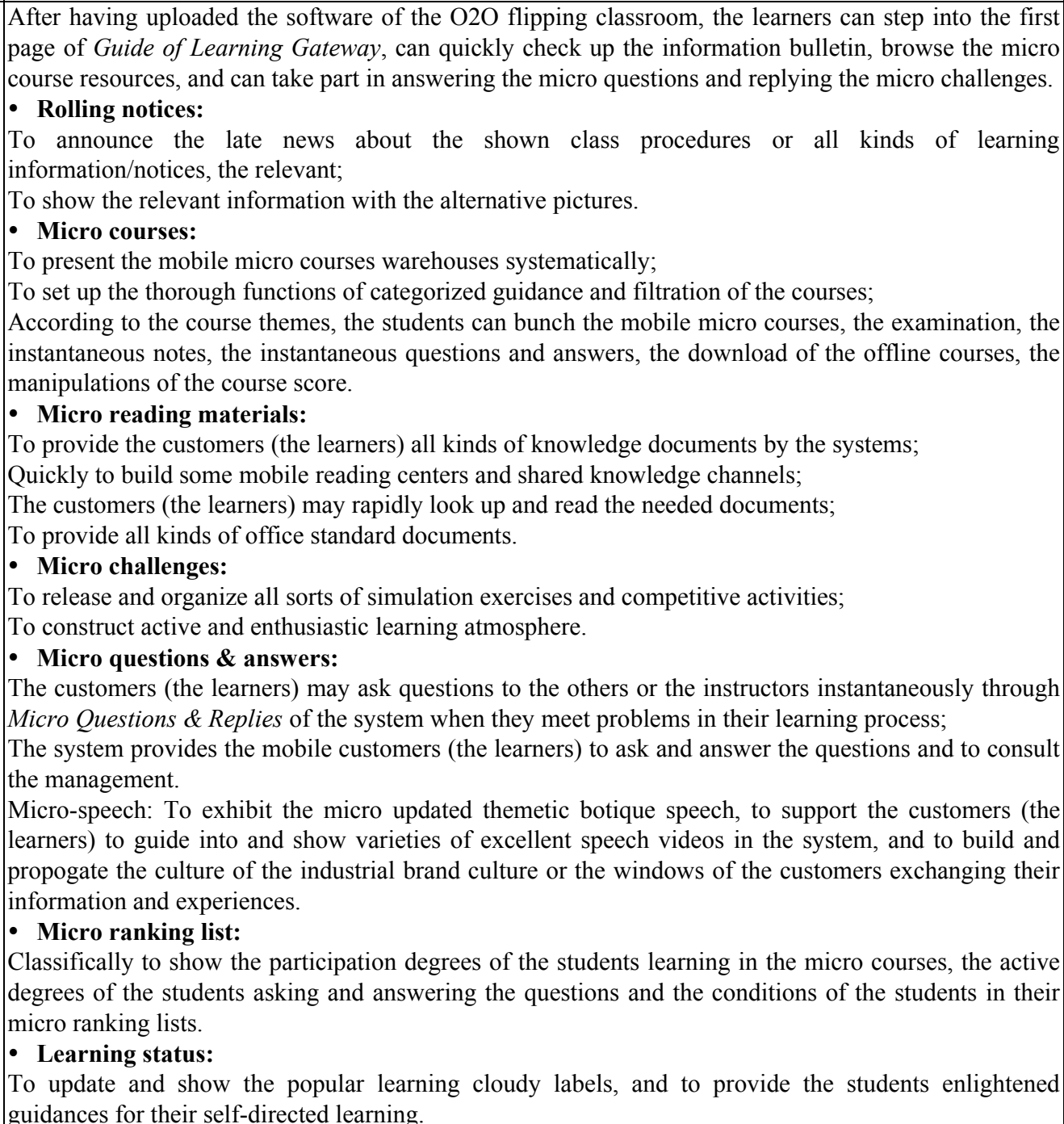 \\
\hline
\end{tabular}


(Table 1 to be continued)

\begin{tabular}{|c|c|}
\hline Functional modules & Detailed descriptions \\
\hline My learning & $\begin{array}{l}\text { The center of My Learning includes My Micro Courses, My Micro Reading Materials, and My Instant } \\
\text { Notices. } \\
\text { - My micro courses: } \\
\text { To offer the students the relevant necessary resources related with the students obligatory micro mobile } \\
\text { courses, and to uniformly manage and remind the students pay attention to their individual collected } \\
\text { mobile micro course resources. } \\
\text { - My micro reading materials: } \\
\text { To offer the students all sorts of key document materials related to learning, and to uniformly manage } \\
\text { all their collected document materials by themselves, and to read, download, and criticize the document } \\
\text { materials online. } \\
\text { - My instant notices: } \\
\text { To support the students to refer and read varieties of instant learning notes written down in their mobile } \\
\text { micro learning processes. }\end{array}$ \\
\hline My activities & $\begin{array}{l}\text { My activities include My Challenges, My Micro Speech, and My Questions \& Replies. } \\
\text { - My challenges: } \\
\text { To show the information about the activities which the customers (the learners) have taken part in the } \\
\text { competitions, including the following information: the general situation of the competitions and the } \\
\text { ranking lists of the customers. } \\
\text { - My micro speeches: } \\
\text { To show the information about all kinds of thematic micro speeches to which the customers (the } \\
\text { learners) have already paid attention. } \\
\text { - My questions and replies: } \\
\text { To show the records of the questions and replies of the customers (the learners). }\end{array}$ \\
\hline Managements & $\begin{array}{l}\text { The customers (the learners) can finish the following work: } \\
\text { To manage the edited information containing the customer's personal basic information, the customer's } \\
\text { head portrait, the login password, etc.; } \\
\text { To manage the following: The documents the customers (the learners) have already downloaded, the } \\
\text { information about the managed customers (the learners) and the learning materials; } \\
\text { To manage the information about what the customers (the learners) have already commented and signed in; } \\
\text { To manage the information about the individual customer (the learner) and the learning customer groups; } \\
\text { To set all kinds of the transmitted rules which remind the customers (the learners); } \\
\text { To check the App version information and the updated products. }\end{array}$ \\
\hline
\end{tabular}

\section{Contrasting the Running Modes and their Elements of the O2O Flipping Classroom and the Traditional Classroom}

Comparing the traditional classroom mode, the $\mathrm{O} 2 \mathrm{O}$ flipping classroom mode has already pertinently improved the key points before class, in class, and after class. The fundamental objects of the $\mathrm{O} 2 \mathrm{O}$ flipping classroom are to foster the students' self-learning abilities, to promote their personalities growth, and to lift the students' learning efficiency. Therefore, the teachers should be encouraged to change their educational concepts and teaching performances, and the teaching should be fit in learning, and the learning should be facilitated by the teaching, and the teaching should be served by the teaching, too. The appearances of excessively paying attention to whether the teachers have taught well or not and to whether the students have exercised sufficiently should be to changed, and the learning procedures before class, in class, and after class should be reconstructed, and the students should be encouraged to participate in the classes, to promote their thinking independence and learning autonomy, to learn actively and individually under the instruction of the teachers', and be courage to learn actively with the convenient learning tools to consolidate their learned knowledge (see Figure 3). 
The Traditional Classroom Mode

The O2O Flipping Classroom Mode

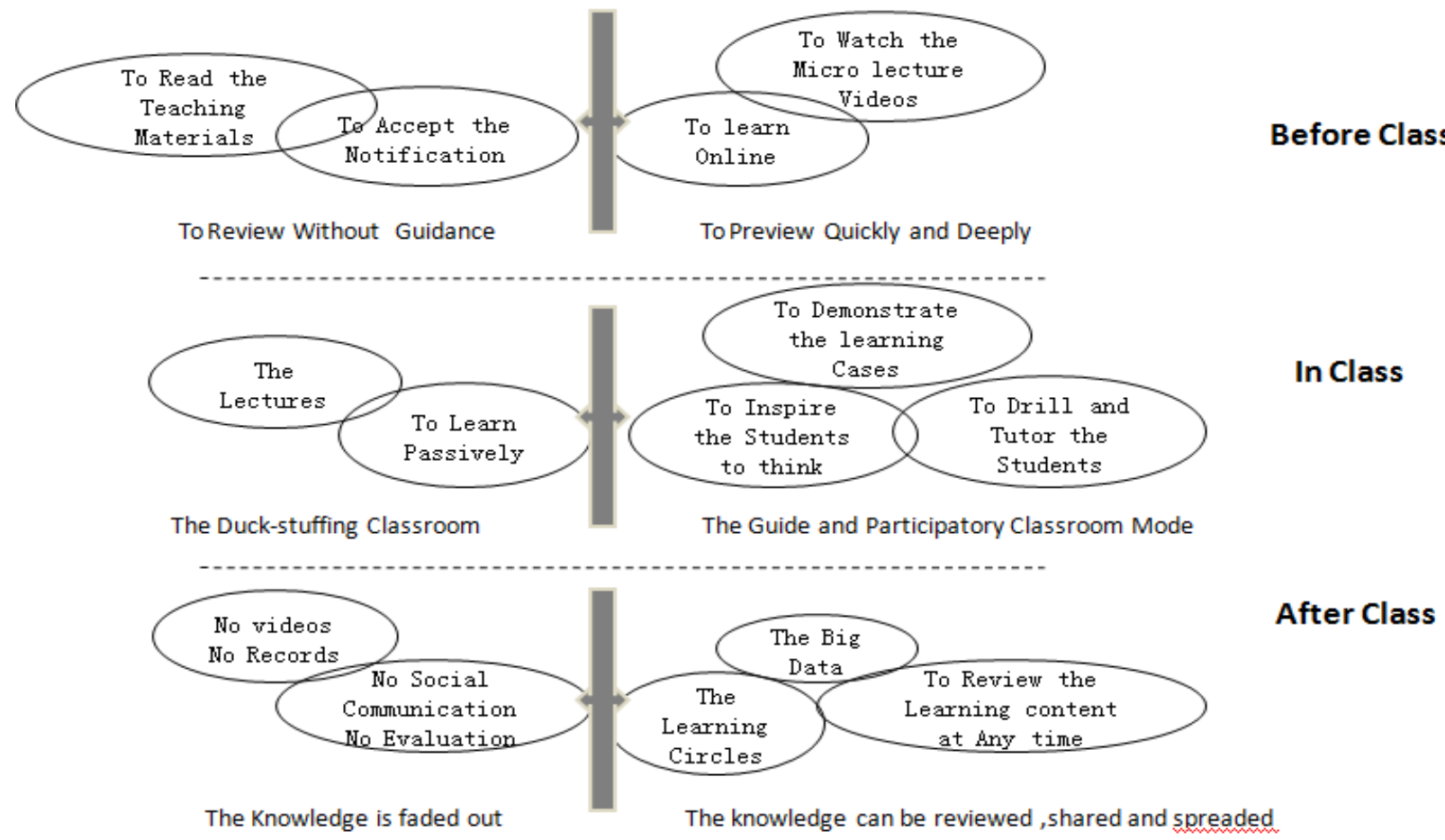

Figure 3. To compare the traditional classroom mode and the $\mathrm{O} 2 \mathrm{O}$ flipping classroom mode.

The elements of the $\mathrm{O} 2 \mathrm{O}$ flipping classroom mode and the traditional classroom mode are contrasted as in Table 2.

Table 2

The Contrasted Illustration of the Elements About the O2O Flipping Classroom and the Traditional Classroom

\begin{tabular}{|l|l|l|}
\hline & Mode of the traditional classroom & Mode based on the O2O flipping classroom \\
\hline Teachers & $\begin{array}{l}\text { Monologue: The knowledge transmitters, } \\
\text { the classroom administrators }\end{array}$ & $\begin{array}{l}\text { Director: The learning instructors and } \\
\text { the class guidance }\end{array}$ \\
\hline Students & The passive spoon-feed receivers & Active participation researchers \\
\hline Teaching forms & $\begin{array}{l}\text { To instruct in class + to finish the } \\
\text { assignments after class }\end{array}$ & $\begin{array}{l}\text { To preview the knowledge deeply + to explore } \\
\text { in class + to communication after class }\end{array}$ \\
\hline Classroom content & To explain the knowledge & $\begin{array}{l}\text { To probe into the problems and to learn } \\
\text { cooperatively }\end{array}$ \\
\hline Technological application & To show the knowledge & $\begin{array}{l}\text { To learn independently, to communicate and } \\
\text { rethink, and to discuss cooperatively }\end{array}$ \\
\hline Evaluation methods & To test in the traditional paper & $\begin{array}{l}\text { Multi-dimensions, multi-forms, } \\
\text { and multi-data sources }\end{array}$ \\
\hline
\end{tabular}

\section{Constructing the Mode of the O2O Flipping Classroom Teaching}

For the combination of the face-to-face teaching mode and the online teaching mode, it will get the best learning effect when both of them have complementary advantages at the same time (Gao \& Pei, 2013). The mode of the flipping classroom teaching proposed by Gerstein (2011) is to divide the class into four stages, i.e., the stage of experiencing learning stage, the stage of exploring the definitions, the stage of constructing meaning and the stage of showing the applications, etc. (Gerstein, 2011). 


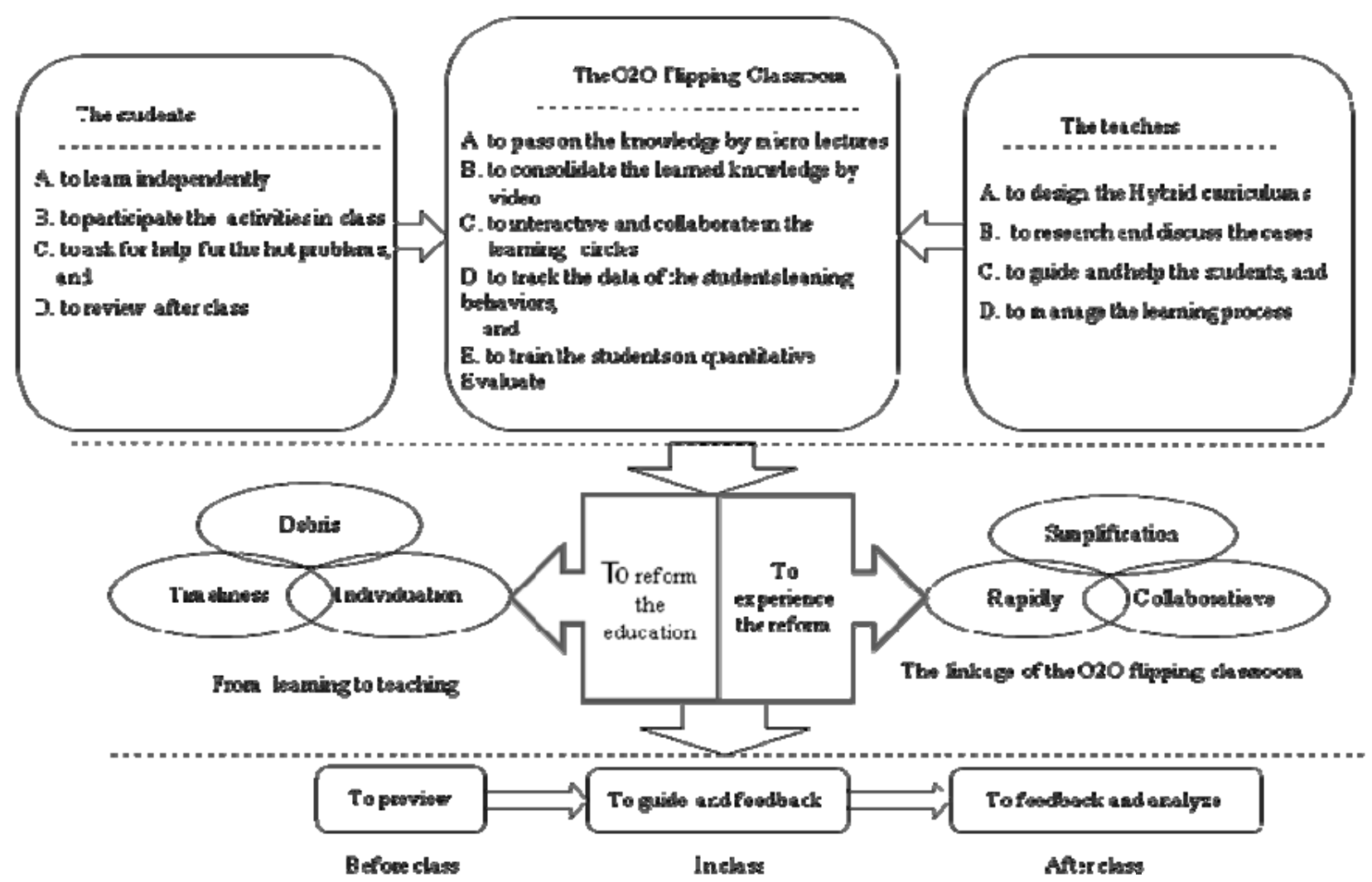

Figure 4. Framework of $\mathrm{O} 2 \mathrm{O}$ flipping class teaching plan.

The $\mathrm{O} 2 \mathrm{O}$ flipping classroom must be constructed on the basis of the functions of the traditional face-to-face teaching and the online teaching, and it will get the best effeiciency by continuous evaluations and transforms. Having refered to the Gerstein's thought, this article creats a design thought on the $\mathrm{O} 2 \mathrm{O}$ flipping classroom teaching mode (see Figure 4). According to the thought of this article, the learning before and after class is priority to the teaching and the learning in class is priority to the teaching offline. In this regard, the students should preview by experiential learning and exploring the key conceptions before class, and they should communicate and exchange their learning experiences and learning achievements online in different learning circles after class by feeding back the information of their learning efficiency to the teachers. In accordance with the students' learning feedback, the teachers are mainly priority to designing class procedures, constructing the teaching and learning materials and to solve the problems which the students have met in their learning processes, and they should also analysis their teaching efficiency and the students' learning demands by the data report; and the teaching activities offline principally contain the study of teaching cases, the guidance of learning, the helpful questions, the management of learning schedules, and so on. The O2O flipping classroom can integrate the transmission of the knowledge in micro courses, the consolidation of the knowledge in class videos, the cooperative interactivities of the learning circles, the tracking data of the student learning actions and the quantitative evaluation of the student learning, etc.. And the teachers should carry out the teaching reforms by the fragmentized learning, the timely assisting teaching, and the recommendation of the student personal learning, and they should carry out the experiential learning reforms with simplification, rapidity and collaboration, and four stages of the flipping classroom teaching may be blended in the three segments before class, in class, and after class. 
The $\mathrm{O} 2 \mathrm{O}$ flipping classroom teaching mode can get better efficiency in cultivating the students' learning interest, enhancing the students' active learning abilities, the operational skills, the abilities of analysis and solving the problems independently, and so on.

This mode not only can eliminate the shortcomings in traditional classroom teaching, but also can help the students to play their dominant roles in their learning processes well, therefore, the students may become active participators in class from primary knowledge receivers as passive "spectators" more freely than ever before, and they can make their learning arrangements in accordance with their own conditions. Of course, all of these above are helpful for the students on different learning levels.

\section{Designing the Procedures of the O2O Flipping Classroom Micro Courses}

Micro lecture, which was called "Knowledge Burst," was brought forward at the earliest by American scholar David Penrose in 2008. At present, there are many explanations about the micro lecture, such as the statement of micro lectures, the statement of classroom fragment, the statement of miniaturized interactive video courseware online, etc.. The scholars, like Jiahou Li, Shengquan Yu, etc., think that the micro lecture is a brief name of the mini course and its focus is on the course. As a kind of mini courses, it should contain perfect segments of teaching design which contains design, exploitation, implement, evaluation, and other links. The micro lecture is one of the major carriers of the flipping classroom. Leming Liang and the others advocate that the flipping classroom may be regarded as a constructed sample of the micro lecture designed mode (Liang, Cao, \& Zhang, 2013). On the basis of the relevant materials, in many core implication modes of the m-learning, the roles of what the customers (the learners) have paid the most attention to are to bunch the mini courses and the learning cases, and the rate of the customers punching mini courses is getting to $76 \%$. With the development of acceptance level of fragmentation learning, the customers (the learners) are putting higher demands for the timelines and the practicability of the learning content.

The choice of the course content is very important during the period of building the m-learning content system. And now, most of people think that most efficient mobile micro lecture modes are chiefly centralized on the short video programs, the animation programs and the documents, etc., and the time of the micro videos should be limited in 15 minutes. In the Netease open courses, the video length are less than 14 minutes in Khan Academy, and are about 10 minutes generally, some of them are even three minutes (Zhang, 2013). In accordance with the suggestions from Jonathan Bergmann and Aaron Sams, the teachers should make a video for every theme in the teaching videos, and the length of the video should be condensed in less than 14 minutes, and the common video's length should be kept in 10 minutes or so (Bergmann \& Sams, 2013).

In future, the design, exploration and application of the micro lectures will be focused continuously, and the massive disciplinary teachers engaging in teaching in first front will increasingly take active part in design and exploration of the micro lectures. More than that, the technologies of design, exploration, and application of the micro-lectures are getting more and more mature, and their availabilities are getting better and better, too. So, is their hardware stronger and stronger? Furthermore, their prices are cheaper and cheaper, and the number of the micro lecture platforms is increasing. Therefore, the demands to the technologies of the disciplinary teachers in the first front and the students will be lower and lower, and the threshold of the micro lecture production will be increasingly lower and lower, and the teachers will pay their attention from the technology and form to the design and originalities of teaching. 
The micro lectures were born for the mode innovation of teaching and learning, but the mode innovation of teaching is really fundamental. And the teaching principle of "learner-center" will not be really embodied until the micro lectures are applied into the flipping classroom teaching mode. Consequently, the teaching efficiency will be promoted steadily finally. Therefore, the authors think that there are three key points to be focused and researched as the following: Firstly, the design of micro lectures should be attached very great attention to. The micro lectures with video often provide the other learning materials. The key of designing the micro lectures is implemented from the analysis of the learners, the learners' demands, etc. in accordance with the teaching aims, and the design and exploration of the micro lectures should obey the rules of the student learning. And then, the teachers can get across a knowledge point with proper teaching approaches and teaching strategies in a short time, often in 10 to 15 minutes. Everyone Can Watch and Understand is treated as the construction goal of Five-Minute Lectures by Open University of China. For example, specific to some social highlight economic issues and the economic problems in life concerned by the public, the curriculum Western Economy combine some fundamental principles of economy and some cases in economic life together with some multi-media technologies of the animations, the three dimensions, the virtual realities, etc., as a result, the abstract and complex knowledge points and fundamental principles can be presented commonly by the teachers with the vivid videos and the teaching content may be easily understood by the students furthermore. The micro lecture videos made in Khan Academy have no head portraits of the teacher and student's, and they are produced mainly by recording the teaching process of solving the problems on the handwriting board with the teacher's synchronizing explanations. Through the application of the flipping classroom teaching mode, these micro videos have been popularized by the students at large. Secondly, in the process of exploring the applied environmental platform of the micro lectures, the good quality micro lecture resources should be integrated to complement each other's advantages, and then the focused effect of the resources will appear finally. And thirdly, when the micro lectures with many single knowledge points are explored intensively, the micro lectures should be constructed with the disciplinary characteristics of serialization, subject and integrity, and make them excellent courses and repository with the collaborative exploration in team.

\section{Evaluating the Learning Achievements Quantitatively with big Data Analysis Technology}

The creation of the big data involves mass of excavations and analysis of the data. Some scholars think that the excavations of educational data and the learning analysis technology are two important applied fields in education (U.S. Department of Education, Office of Educational Technology, 2012). The connotation of the educational data excavation should be committed by quantizing, analyzing and modeling the learning behaviors and the learning process (Zhang, 2013), and its aims are just to analyze the data produced in the process of teaching and learning in the ways of statistics, machine learning, and data excavation, etc. (Zhu \& Shen, 2013). The objects of learning analysis are the students and not only may the analysis objects be refined, but also may the applied mode be constructed, and consequently the teaching concept and the teaching strategy will be fulfilled indeed. In the background of big data, the technologies of excavating and analyzing the educational big data are helpful for the teacher teaching reforms (Wang, 2013). And the teachers can know the learning habits, the learning behaviors, and the learning processes with big data analysis in order that they can find the best teaching approaches and instruct the students preferably. In addition, the teachers can adapt some personal teaching strategies in accordance with the individual student, and find some problems timely, and to intervene with and evaluate them correctly. Therefore, the teaching qualities and effects may be promoted remarkably (He, 2014). 
As the traditional teaching concepts being subverted in big data era, the teachers should not only impart the knowledge, they should also learn to construct learning resources and to analysis the data (see Figure 5). And sometimes should learn to model and analysis the data in order to prove that some innovated teaching approach is feasible. With the arrival of smart learning era, the demands for the teachers and the students are getting higher and higher, and the learning ways and the teaching modes will be thoroughly overturned, and more and more people are beginning to accept the concept of ubiquitous learning with the popularization of mobile learning, and they can learn and teach at anytime, anywhere.

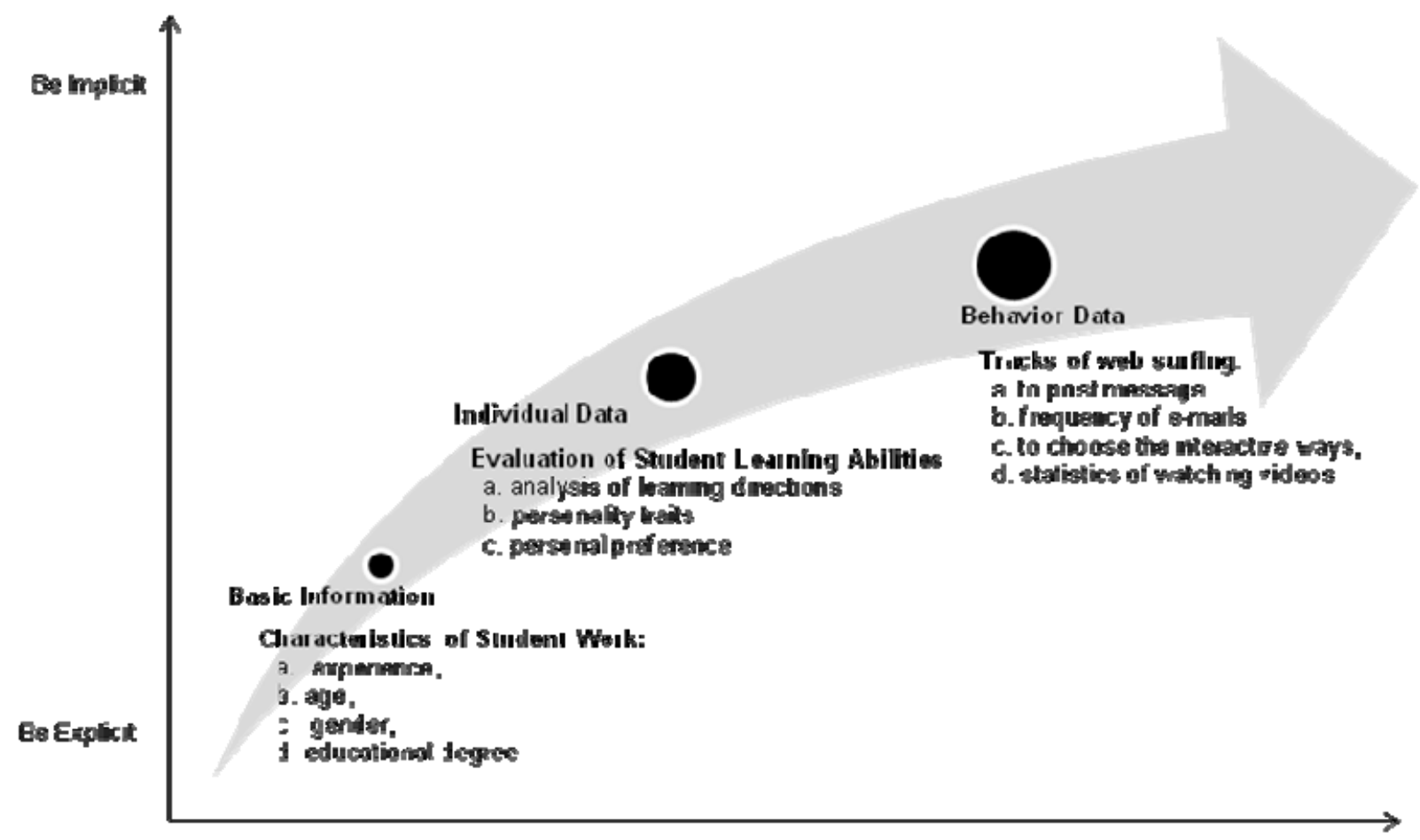

Stıucturel Butt

Unshuctin al Data

Figure 5. Schematic diagram of data attribute.

In order to quantitatively assess the learning and to trace, analysis and evaluate the relevant data, the data in the system needs to analysis, extract and clean out in time, the shown data and characteristics of the $\mathrm{O} 2 \mathrm{O}$ flipping classroom learning platform just as those in Schematic Diagram 3: Firstly, some of the data in the systematic database is implicit, and the others is explicit. Commonly, the explicit data is mainly the structural data, such as the students' basic information, the occupational history, the educational status, etc.. Secondly, the implicit data is often mainly the unstructured data, including varieties of the students learning behaviors, such as the condition of the students' interactivities, the choice of their interactive ways, the conditions of browsing the websites or the videos; and Thirdly, there is a kind of data between the explicit and the implicit, for instance, the student competent assessments, the analysis of the learning directions, personal traits, the individual hobbies, the submitted menu online, the credential materials, and most of these above are the semi-structured data. It is helpful to use the unified objective and quantitative data for showing the learning efficiency. And with continual use and the time and time again tests, a strong learning resource and knowledge problem warehouse is accumulating gradually. And all of the learning achievements are being recorded, and all the 
information about students' learning is being collected. Therefore, the information will offer the individual learner some suggestions, and then it will change into a growth path of the learners' learning finally.

The traditional approach of the learning assessment is to make a questionnaire inquiry, to analysis all the main influencing factors of learning effects and demands according to the pre-set learning assessment models. It is not only in real time and on dynamic status to analysis the big data. Comparing with the traditional relative statistic status and pre-set model of learning analysis approach, but also will it be more efficient and convenient to realize the future prediction facing to the learners by excavating the relevant data. As the learning environment is getting more and more digital, the learning assessment and the learning demands are quantified increasingly. The analysis of variety of relevant platform data above shows that the application of the data analysis may be feasible for the realization of learning quantitative assessment, the commendation of the precise personality, the analysis of learning demands, etc..

To analysis the quantitative assessment by big data is similar to the implication of online opinion analysis. From the different data origin containing the student social media Web pages, the communication information in learning circles, the e-mails, etc., the information which is influence learning can be extracted and filtrated with the text semantic emotional analysis mode, and the information relevant to the factors which is to improve the students' learning achievements may be found and the students' learning demands may be predicted by the connotative information which can be excavated in the data by the analysis technologies, such as the analysis of the texts, the analysis of the correlations in different dimensions, the analysis of the trends and so on. The students' demands and the open problems which can be found in time can be guided and improved to make the offline teaching more pertinent to monitor the students learning behaviors like the conditions of the communications and interactive (here they refer to the frequency and directions of the interactive) and the choices of learning circles, and so on. For example, if the most of the students learn some knowledge point again and again, and if many key words related with this knowledge point appear in the learning circle and the other interactive links, it will indicate that the students may be interested in the modularity-based knowledge, and there are some learning difficulties, and the teachers can refine and explain this knowledge point relatively. If few of the students can finish their learning on some whole lecture, it will indicate that this theme is unpopular with the students, and the teachers should analyze the reasons which have caused the problems on the micro lecture and the choice of the learning content. And the analysis of the students' online tested learning results may reveal the learning outcomes more directly, and it may offer some inferences for the offline teachers' curriculum designs. To sum up, the data analysis above may be divided into two categories: emotion perceptions and behavior perceptions. The data of the emotion perceptions origins from the choice of the learning media, the choice of the learning circles, the learning directions, the learning capacity assessments, and so on. And the data of the behavior perceptions come from all kinds of online interactive behaviors and the conditions of the browsed pages on network, and so on. By analyzing the data of emotion perceptions and behavior perceptions, a complex quantitative evaluation can be evaluated and assessed in many times, and the individual services, the precise commendations and the other related analysis can be offered simultaneously, too (see Figure 6).

When the real system data is extracted, the invalid data, the dirty data, the fault data should be found firstly, then to delete the seriously missed data from the samples, and then have the distinct contradict data roll-backed into the data banks, and lastly to choose the highly relevant data and to give up the irrelevant one. 


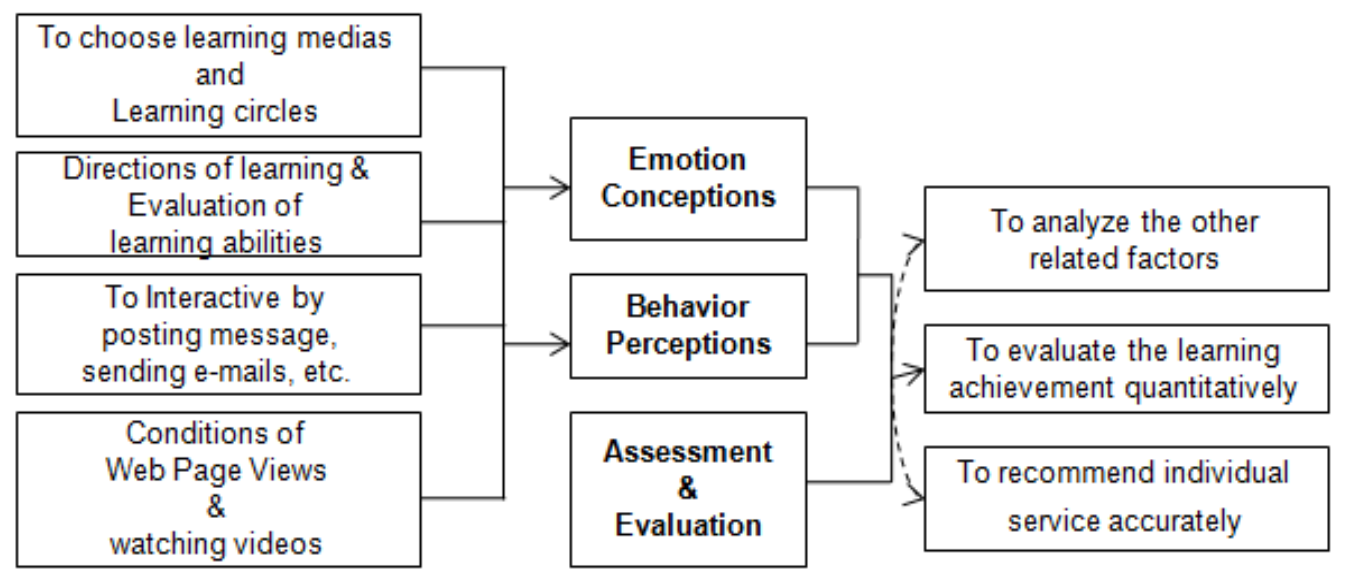

Figure 6. Learning related factors structural chart of learning quantitative evaluation.

\section{Conclusions}

The smart learning era demands not only students' corresponding learning abilities and certain skills of the network implication, but also the teachers' promotion in their own teaching skills of constructing resources, curriculum design, and even the data analysis and better teaching concepts. In that case, teachers may know the accurate dynamic learning demands of the learners and offer them concrete teaching instructional guidance and necessary help in time.

The $\mathrm{O} 2 \mathrm{O}$ flipping classroom model based on mobile learning can effectively use the educational big data and the teaching evaluation of the learning analysis technologies. In the smart learning era, the students should not only have some corresponding learning abilities and certain skills of the network implication, but also should the teachers promote their own teaching skills of constructing resources, curriculum design, and even the data analysis and better teaching concepts, and the teachers may know the accurate dynamic learning demands of the learners and offer the students concrete teaching instructional guidance and necessary help in time.

\section{References}

Bergmann, J., Overmyer, J., \& Wilie, B. (2012). The flipped class: What it is and what it is not [EB/OL]. Retrieved April 14, 2012, from http://www.thedailyriff.com/articles/the-flipped-class-conversation-68.php

Bergmann, J., \& Sams, A. (2012). How to make videos your students will love [EB/OL]. Retrieved May 21, 2012, from http://www.eschoolnews.com/2012/05/21/how-to-make-videos-your-students-will-love/

Dewey, J. (2001). Democracy and education (p. 46). C. X. Wang, Trans.. Beijing: People's Education Press.

Gao, D. H., \& Pei, L. Y. (2013). Construction and application of teaching mode based on network. Modern Educational Technology, 23(1), 80-83.

Gerstein, J. (2011). The flipped classroom [OL]. Retrieved from http://www.scoop.it/t/the-flipped-classroom

He, K. K. (2014). Aspects of big data. e-Education Research, 35(10), 8-16.

Liang, L. M., Cao, Q. Q., \& Zhang, B. H. (2013). Research on a micro-lecture design model through comparative case study. Open Education Research, 19(1), 65-7.

U.S. Department of Education, Office of Educational Technology. (2012). Enhancing teaching and learning through educational data mining and learning analytics: An issue brief. Washington, D.C. [DB/OL]. Retrieved May 20, 2013, from http://www.ed.gov/edblogs/technology/files/2012/03/edm-la-brief.pdf

Wang, Z. Y. (2013). Out of old education and into the wave of big data. Information Technology Education of Primary and Secondary Schools', (10), 30-31. 
Zhang, Y. J. (2013). To meet the challenges from the big data brought by education. Information Technology Education of Primary and Secondary Schools', (10), 26-29.

Zhang, J. L. (2013). Discuss the key factors of flipping classroom teaching mode. Distance Education in China, (10), 59-65.

Zhu, Z. T., \& Shen, D. M. (2013). A new mode of educational technological research based on big data. e-Education Research, $34(10), 5-13$. 